Original scientific paper

\title{
EFFECT OF RADIAL CLEARANCE ON BALL BEARING'S DYNAMICS USING A 2-DOF MODEL
}

\author{
Ambrozkiewicz, B. ${ }^{* * *}$; Litak, G. ${ }^{*}$ Georgiadis, A. ${ }^{* *}$; Syta, A. ${ }^{* * *}$; Meier, N. ${ }^{* *}$ \& Gassner, A..* \\ * Department of Automation, Lublin University of Technology, Nadbystrzycka 36, 20-618 Lublin, \\ Poland \\ ** Institute of Product and Process Innovation (PPI), Leuphana University of Lüneburg, \\ Universitätsallee 1, 21335 Lüneburg, Germany \\ *** Department of Production Computerisation and Robotisation, Lublin University of Technology, \\ Nadbystrzycka 36, 20-618 Lublin, Poland \\ E-Mail: b.ambrozkiewicz@pollub.pl,g.litak@pollub.pl,georgiadis@leuphana.de,a.syta@ pollub.pl, \\ nmeier@leuphana.de, alexander.gassner@stud.leuphana.de
}

\begin{abstract}
In the present work, a method for the analysis of short time intervals in ball bearings is proposed. We study the effect of the internal clearance on the dynamics of ball bearings using recurrence plots and the recurrence quantification approach. In the proposed method, we focused on the analysis of dynamic states generated from the 2-DOF mathematical model, to which a function changing the damping coefficient in the clearance domain was added. Chosen recurrence methods showed the specific dynamic responses by different values of the radial clearance. The effect of self-consistency concerning the damping effect and vibration development is confirmed. The proposed method can be useful for the prediction of variable radial clearance in time by analysis of the acceleration response of ball bearing during its operation.

(Received in May 2021, accepted in July 2021. This paper was with the authors 1 week for 1 revision.)
\end{abstract}

Key Words: Ball Bearings, Radial Internal Clearance, Nonlinear Dynamics, Recurrence Plots, Recurrence Quantification Analysis

\section{INTRODUCTION}

Proper functioning of various mechanical systems depends on the correct dynamics of the rotational components, i.e. rolling-element bearings, gears, shafts, or couplings, that carry the complex load and transfer motion during its operation. Among mentioned elements, bearings demand the most complex manufacturing process including heat-treatment [1,2] and machining [3, 4], which has to provide a high quality of rolling surfaces and the best possible bearing's performance [5, 6]. The real-time diagnostics of rolling-element bearings is part of the strategy of Industry 4.0, to prevent unexpected damages leading to unscheduled downtime or economical losses. Recently, more and more often the introduced strategy in industrial solutions is based on increased computational capabilities, digitalization, online-condition monitoring, model-based prediction, etc. [7, 8].

Ball bearings have one of the most complex and unpredictable dynamics, this is related to the many sources of vibrations $[9,10]$, i.e. defects of bearing elements, shape errors, misalignments, specific design, external factors, etc. The identification of characteristic frequencies is related to damages of bearing, which have been widely discussed over years and its description is based on the bearing design and operational velocity [11]. It is known that quality of rolling surfaces (waviness and roundness) has a significant influence on the vibrations generated by ball bearings, in this area, a quantitative investigation has been performed [12]. Another important feature with an undisputed influence on the ball bearing's dynamical response is the radial internal clearance (RIC) defined as the total distance through which one bearing's ring can be displaced relative to the other in the radial direction. Primarily, the importance of selecting the optimal clearance to the application refers to the bearing life and its 
value depends on subjected load, operating temperature, and fitting on the shaft and in housing. After considering above mentioned feature, to ensure the longest life expectancy of ball bearing, the operating clearance should be around zero. A value of deviating too small or too big from the operating clearance will lead to the premature wear of rolling surfaces emerging with elevated temperature, increased friction torque, or high amplitudes of vibrations.

The effect of radial clearance on the dynamics was the subject of the study both analytically and experimentally over recent years. For the first time, Tiwari et al. [13] found periodic, subharmonic, and chaotic regions in the dynamical response of ball bearing caused by the variable radial clearance. Changqing and Qingyu [14] proposed the extended 5-DOF mathematical model taking into consideration radial clearance, shape errors, and loads for nonlinear analysis of rotor system. The clearance effect significantly influenced the variation of the system's stability regarding the other terms in the equation of motion. Another important aspect is the identification of radial clearance during bearing operation, Mišković et al. [15] studied the influence of grease contamination on the clearance by thermographic inspection. Similar research referring to plain bearings was conducted by Miler et al. [16] additionally studying the influence of the clearance on the friction coefficient. Xu et al. [17] in their research compared the acceleration response by different values of radial clearance obtained by the experimental and mathematical methods. They proposed the RMS and spectral centroid as indicators determining the operating radial clearance. One of the recent approaches for online clearance monitoring is the application of artificial-intelligence-based methods in form of neural networks (ANN) $[18,19]$ referring to the RMS value of an acceleration signal.

It has been investigated, that radial clearance plays an important role in the dynamics of ball bearings and strongly influences their performance during operation. By the experimental analysis, it has been observed, that the decrease of the clearance value affects the damping ratio in the ball bearing. To follow the research of Yakout et al. [20], we assume in our research the variable damping coefficient in the equation of motion referring it to the variable internal clearance. The variable stiffness in the ball bearing depends in most cases on the contact caused by subjected load or defects on the rolling surfaces [21]. On the other hand, the damping in ball bearings is dependent on operating velocity, lubrication, fitting and material deformation caused by Hertzian deformation on rolling surfaces [22, 23]. To study the effect of the radial clearance on the dynamic response of a ball bearing, we apply the recurrence-based methods, i.e. recurrence plots (RPs) and recurrence quantification analysis (RQA). The proposed method is applied to the analysis of short-time series and has been successfully used in the diagnostics of mechanical systems [24-26].

The remainder of this paper is as follows. In Section 2, the 2-DOF model of rolling-element bearing is discussed. In the next Section 3, the simulation results are presented comparing the standard approach with constant damping coefficient and linearized damping factor in the clearance domain. Conclusions summarize the research and the next steps in the research development are established.

\section{NONLINEAR MODEL OF BALL BEARING}

A mathematical model is the process of encoding and decoding reality, in which a real phenomenon is presented in formal numerical description by a casual structure [27-29]. Regarding the 2-DOF model of rolling-element bearing, it can be considered as a spring-mass resonator, in which balls are treated as nonlinear contact springs and the raceway of the outer ring is treated as a deformable, compliant body (Fig. 1). Then the outer ring is fixed in the housing and the inner ring and shaft's journal are considered as one mass called rotor-bearing system. According to the Hertzian theory, elastic deformations between rolling surfaces produce non-linear phenomena between variable forces and deformations resulting in 
temporary in-contact and no-contact. Another important aspect influencing the bearing's vibrations is the shape errors [30] in form of a number of undulations over the raceway's diameter with specific amplitude.

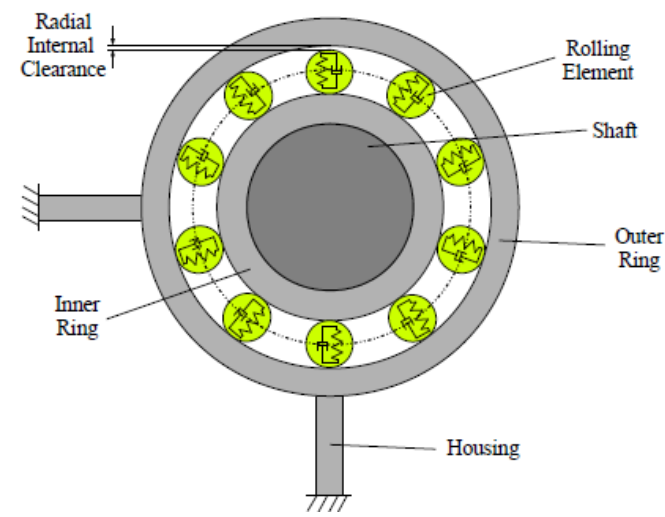

Figure 1: The schematic diagram of rolling element bearing.

For the analysis of the influence of the damping coefficient on the dynamical response, we continue the development of the 2-DOF model discussed in the following article [31]. Applied dimensionless model provides satisfying results for study the dynamical response of rollingelement bearings and its dimensionless form introduces the understanding of applied terms in the domain of crucial parameter, in our case the radial internal clearance. The type of ball bearing applied to the simulation is 6309 , its real design parameters are stated in Eq. (1) determining the cage velocity (same as the velocity of rolling elements):

$$
\omega_{c}=\frac{\omega_{s}}{2}\left(1-\frac{D}{d_{p}}\right)
$$

where:

$\omega_{c}$ - cage velocity,

$\omega_{s}$ - shaft velocity,

$D$ - diameter of rolling element,

$d_{p}-$ pitch diameter.

In the calculation of deformations $\delta_{i}$ in the mathematical model according to the Hertzian contact theory, the eccentricity effect and shape errors are taken into account Eq. (2):

where:

$$
\delta_{i}=\delta_{x s} \cos \left(\psi_{i}\right)+\delta_{y s} \sin \left(\psi_{i}\right)-R I C-A_{\text {in }} \sin \left(n_{\text {in }} \psi_{0}\right)-A_{\text {out }} \sin \left(n_{\text {out }} \psi_{0}\right)
$$

$\delta_{x s}, \delta_{y s}-$ deformations of rolling surfaces in vertical $x$ and horizontal $y$ directions,

$\psi_{i} \quad-$ the angular position of each rolling element,

RIC - radial internal clearance,

$A_{\text {in }}, A_{\text {out }}$ - amplitude of undulation on the inner and outer raceway,

$n_{\text {in }}, n_{\text {out }}$ - number of undulations on the inner and outer raceway,

$\psi_{0}-$ the angular position of the first ball in a row.

The state vector for the 2-DOF model with above-described assumptions is formulated in the following way Eq. (3):

where:

$$
\left\{\begin{array}{c}
\frac{d \delta_{x s}}{d t} \\
\frac{d \delta_{y s}}{d t} \\
\frac{d \dot{\delta}_{x s}}{d t} \\
\frac{d \dot{\delta}_{y s}}{d t}
\end{array}\right\}=\left\{\begin{array}{c}
\dot{\delta}_{x s} \\
\dot{\delta}_{y s} \\
F_{x}+e c c \omega_{s}^{2} \cos \left(\omega_{s} t\right)-K_{x x s}-c_{x} \dot{\delta}_{x s} \\
F_{y}+e c c \omega_{s}^{2} \cos \left(\omega_{s} t\right)-K_{y y s}-c_{y} \dot{\delta}_{y s}
\end{array}\right\}
$$


$F_{x}, F_{y} \quad$ - forces subjected to the bearing in $x$ and $y$ directions,

ecc - eccentricity,

$K_{x x s}, K_{y s s}-$ Hertzian contact forces in $x$ and $y$ directions,

$c_{x}, c_{y} \quad$ - damping coefficient in $x$ and $y$ directions.

Following the Yakout et al. [20] research, we study the influence of the radial internal clearance on the dynamic response of the ball bearing. In Table I, the analysed model parameters are specified, the variable clearance in the range of $1-50 \mu \mathrm{m}$ and the variable damping coefficient decreasing with the increase of clearance value (Fig. 2). The damping is changed with step 0.01 every $5 \mu \mathrm{m}$, the results of the dynamical response are compared by the traditional approach with constant damping factor and variable as described. The remaining model parameters taken for simulation are constant as in the work [31], blue line in Fig. 2 refers to the constant damping factor equal to 0.01 in the unit of clearance (from previous paper). This time, for the analysis, the acceleration response obtained from the vertical axis is taken into account.

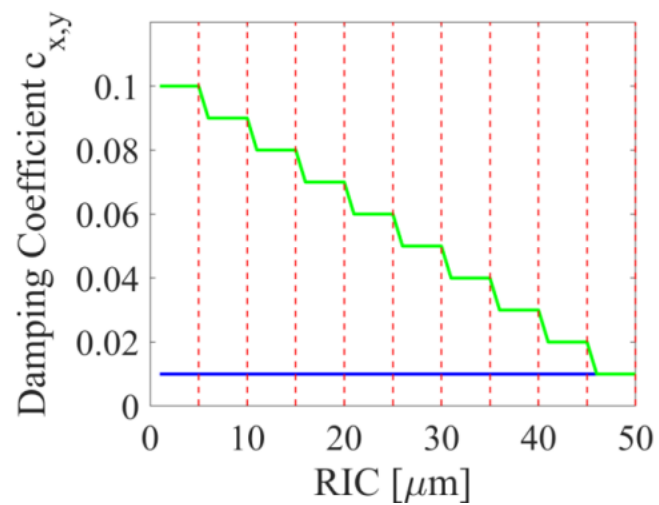

Figure 2: Damping coefficient versus RIC. The green refers to the present studies, while the blue line refers to the constant damping factor.

Table I: Parameters of the nonlinear mathematical model considered in the simulation.

\begin{tabular}{|c|c|c|c|}
\hline Parameter & Symbol & $\begin{array}{c}\text { Value of } \\
\text { dimensionless } \\
\text { term } \\
\text { (without unit) }\end{array}$ & $\begin{array}{c}\text { Value of } \\
\text { real-term } \\
\text { (with unit) }\end{array}$ \\
\hline $\begin{array}{c}\text { Clearance range } \\
{[\mu \mathrm{m}]}\end{array}$ & $R I C$ & $0.05-2.50$ & $1-50$ \\
\hline $\begin{array}{c}\text { Eccentricity } \\
{[\mu \mathrm{m}]}\end{array}$ & $e c c$ & 0.1 & 2 \\
\hline $\begin{array}{c}\text { Damping coefficient } \\
\text { in } x, y \text { axis } \\
{[\mathrm{Ns} / \mathrm{m}]}\end{array}$ & $c_{x}, c_{y}$ & $0.01-0.1$ & $265.7-2657.0$ \\
\hline
\end{tabular}

\section{SIMULATION RESULTS AND DISCUSSION}

The simulation of the mathematical model of rolling-element bearing is conducted in Matlab software using the ODE45 algorithm for solving differential equations with the constant time step equal to 0.01 . The initial conditions, i.e. deformations $\delta$ and velocities $\dot{\delta}$ are set to zero and for the analysis, the stable state of acceleration $\ddot{\delta}$ is taken into account. The effect of variable clearance and damping is studied for the single-row ball bearing 6309 for which in Table II, the radial clearance classes are defined. The motivation of applying classes from $\mathrm{C} 2$ to $\mathrm{C} 4$ into the mathematical model, that they preponderate in the real applications. 
Table II: Clearance classes for ball bearing 6309 considered in the simulation.

\begin{tabular}{|c|c|c|c|c|}
\hline Clearance class & $\mathbf{C 2}$ & $\mathbf{C N}$ & $\mathbf{C 3}$ & $\mathbf{C 4}$ \\
\hline $\begin{array}{c}\text { Clearance range } \\
{[\mu \mathrm{m}]}\end{array}$ & $1-11$ & $6-23$ & $18-36$ & $30-51$ \\
\hline
\end{tabular}

The variable contact between rolling surfaces according to the Hertzian contact theory and the application of the Heaviside function in the numerical simulations allow expecting a strongly non-linear character of obtained dynamical response. By small values of clearance $(\mathrm{C} 2$ class and lower range of $\mathrm{CN}$ ) and tight alignment of rolling elements, the significant influence on the dynamical response will have frictional forces between rolling surfaces. With bigger values of clearance in the ball bearing, the freedom between balls and raceways increases, which results in temporary contact and contact loss. Then, we expect higher amplitudes of the acceleration response coming from the relative contact between rolling elements and the raceway of inner and outer rings. In Fig. 3, two acceleration responses are presented for two different clearances, i.e. $15 \mu \mathrm{m}$ (normal clearance $-\mathrm{CN}$ ) and $42 \mu \mathrm{m}$ (clearance greater than $\mathrm{C} 3$ - C4). At the first glance, the magnitude for $42 \mu \mathrm{m}$ clearance is bigger than $15 \mu \mathrm{m}$, additional observations between two responses are a stronger influence of nonlinear effects in case of bigger clearance. Over the periodic solution overlaps other sub/super-harmonics or other frequencies obtained during the bearing's operation. Referring to the observation described in the article [13], the variable clearance leads to the bifurcations in the response of the rotorbearing system and possible chaotic solutions. This observation brings the motivation to study the acceleration response with nonlinear methods describing the dynamical behaviour qualitatively and quantitatively.
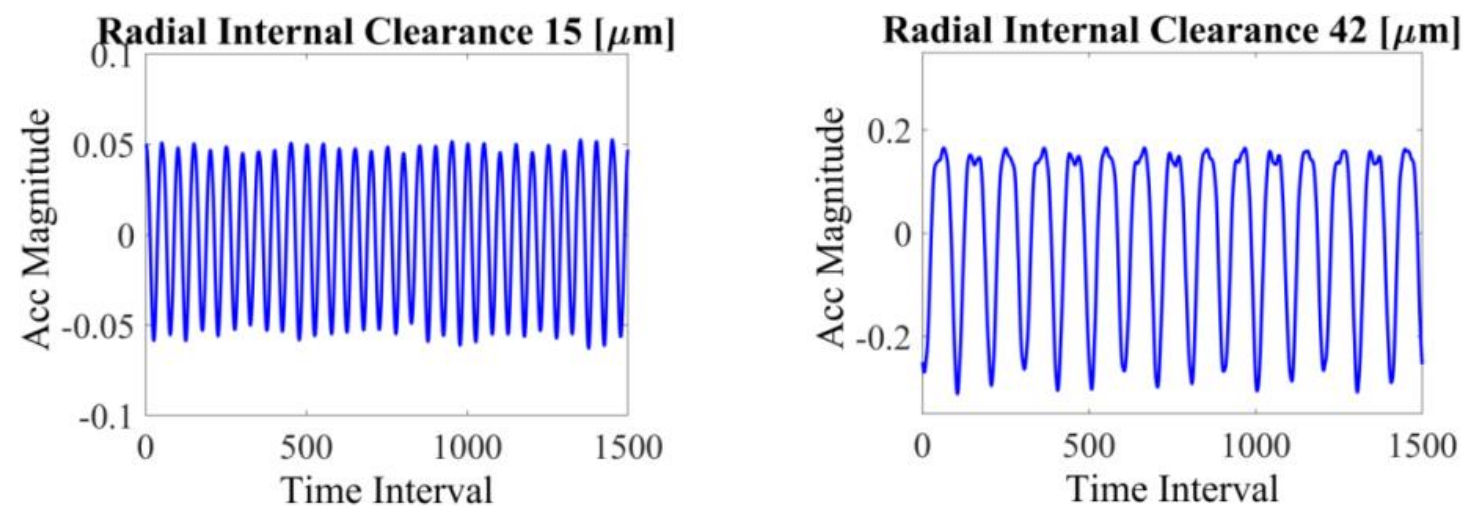

Figure 3: Acceleration time series for $R I C=15 \mu \mathrm{m}$ (left side) and $R I C=42 \mu \mathrm{m}$ (right side).

A sensitive method applied to the analysis of nonlinear time series and detection of slight quantitative and qualitative changes in the dynamical system is the recurrence analysis [32]. The proposed method is divided for the presentation of qualitative changes in form of recurrence plots (RPs) [33] and quantitative in series of recurrence quantificators [34]. At first, the recurrence plots method was applied for visualization of system trajectories in form of 0-1 matrix corresponding to non-recurrence and recurrence state if the system meets roughly the same point in the phase space. The method was insufficient, as only the general behaviour of the dynamical system could be detected and recognized. For the development of the RP method, the recurrence quantificators were introduced, which are based on the obtained matrix and calculated according to the specific formula. The indicators can be split into the following groups based on the number of recurrence points, diagonal lines, vertical lines, recurrence time, and probability. 


\subsection{Recurrence plot $(\mathrm{RP})$ analysis}

The analysis starts with the reconstruction of the phase space from single time series for each considered radial clearance, for which the constant embedding parameters were taken into account, i.e. time delay $\tau=5$, dimension $m=5$, the threshold $\varepsilon$ is automatically calculated by application of the constant value of the recurrence rate $R R=5 \%$ (percentage of points in the recurrence plot - Fig. 4). To ensure the consistency of obtained responses, the constant number of data points was considered $N=1500$ for each clearance, both for cases with constant and variable damping coefficients. In Fig. 4, two various patterns were obtained for varying values of radial clearance. The recurrence plots presented in Fig. 4 are visualization of the recurrence matrix contain zeros at times $i$ and $j$ given by the formula:

$$
R_{i, j}^{\varepsilon}=\Theta\left(\varepsilon-\left\|\overrightarrow{x_{l}}-\overrightarrow{x_{j}}\right\|\right), \quad \overrightarrow{x_{\imath}} \in \mathbb{R}^{m}, \quad i, j=1, \ldots, \mathbb{N},
$$

where $\Theta$ is the step function, $\|\cdot\|$ are distance function (Euclidean in our case) and $\varepsilon$ is the threshold value. In other words, if two states in time are similar (close enough to each other), then the recurrence occurred (identity in the recurrence matrix and blue dot in the recurrence plot). Otherwise, there is no recurrence (zero in the recurrence matrix and white dot in the recurrence plot).
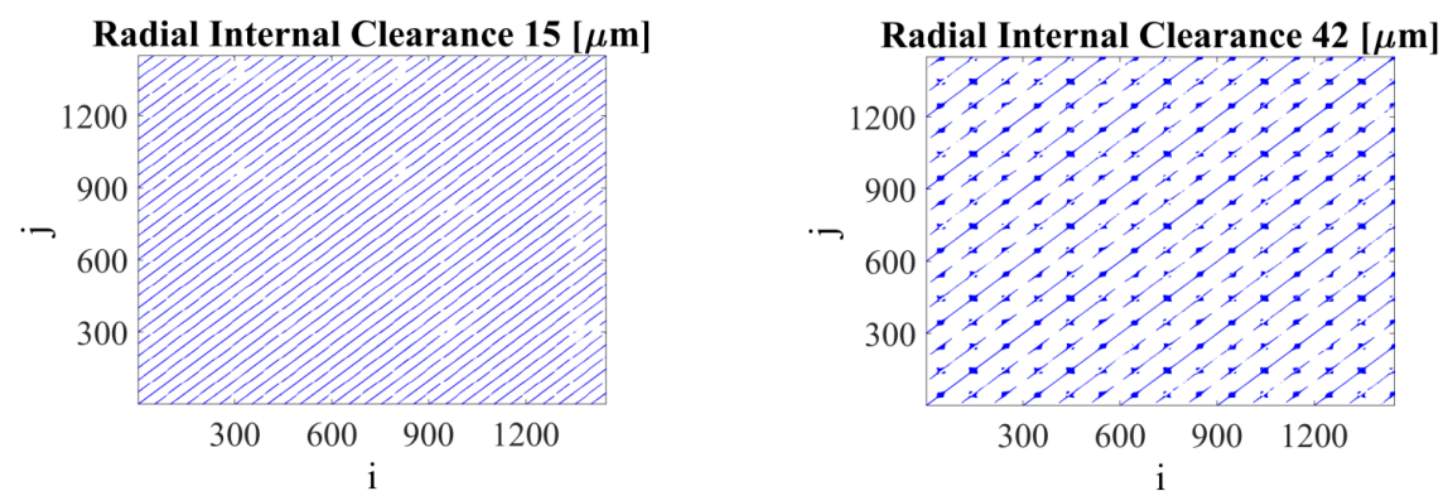

Figure 4: Recurrence plots for $R I C=15 \mu \mathrm{m}$ (left side) and $R I C=42 \mu \mathrm{m}$ (right side; cases with modified damping coefficient).

Referring to the $R I C=15 \mu \mathrm{m}$, we obtain the periodic solution, which is reflected in uninterrupted diagonal lines aligned at the same distance from each other. Only minor modulations are observed caused by another characteristic frequency in the spectra with a small amplitude. In the case of clearance $R I C=42 \mu \mathrm{m}$, there are many isolated points in form of clusters along diagonals, and the response is more nonperiodic. The difference between the dynamical response of considered clearances is explicit, but for a better understanding of the bearing's behaviour by the effect of variable $R I C$, the more quantitative RQA method will be applied.

\subsection{Recurrence quantification analysis (RQA)}

For the calculation of the recurrence quantificators, the CRP Toolbox is applied authored by Marwan et al. [35] from Potsdam Institute for Climate Impact Research. The toolbox calculates 13 main recurrence quantificators, but for the analysis, only 9 of them were considered, which provided quantitative information on the acceleration response by variable clearance. The comparative analysis is based on the comparison of the influence of the damping coefficient on the dynamical behaviour of ball bearing. On each plot, the dashed lines corresponding to the range of specific clearance classes have been drawn, to observe the change of each quantificator within the clearance domain. The quantificators have been divided into groups dependent on their character. 
- Recurrence quantificators based on the diagonal lines:

In Fig. 5, the response of determinism DET and averaged diagonal length $L$ are depicted. Determinism is the ratio of points forming diagonal lines characteristic of periodic vibrations. The value of determinism is close to 1 up to $40 \mu \mathrm{m}$ showing the range of clearance when the system is predictable. The variable damping reduces the fluctuations from around $30 \mu \mathrm{m}$ clearance and shows the decrease of the determinism by $\mathrm{C} 3$ and $\mathrm{C} 4$ clearance classes. Referring to the $L$ quantificator has a distribution with unordered character. In the range of $\mathrm{C} 2$ clearance, strong fluctuations are observed, and only for $\mathrm{CN}$ clearance, the bearing starts to stabilize on a relatively constant level. In response to the constant damping coefficient, three points denoting discontinuity are observed. On the other hand, the modified damping reduces this number to two points, the middle of $\mathrm{C} 2$ clearance and the limit between $\mathrm{CN}$ and $\mathrm{C} 3$ clearance class.
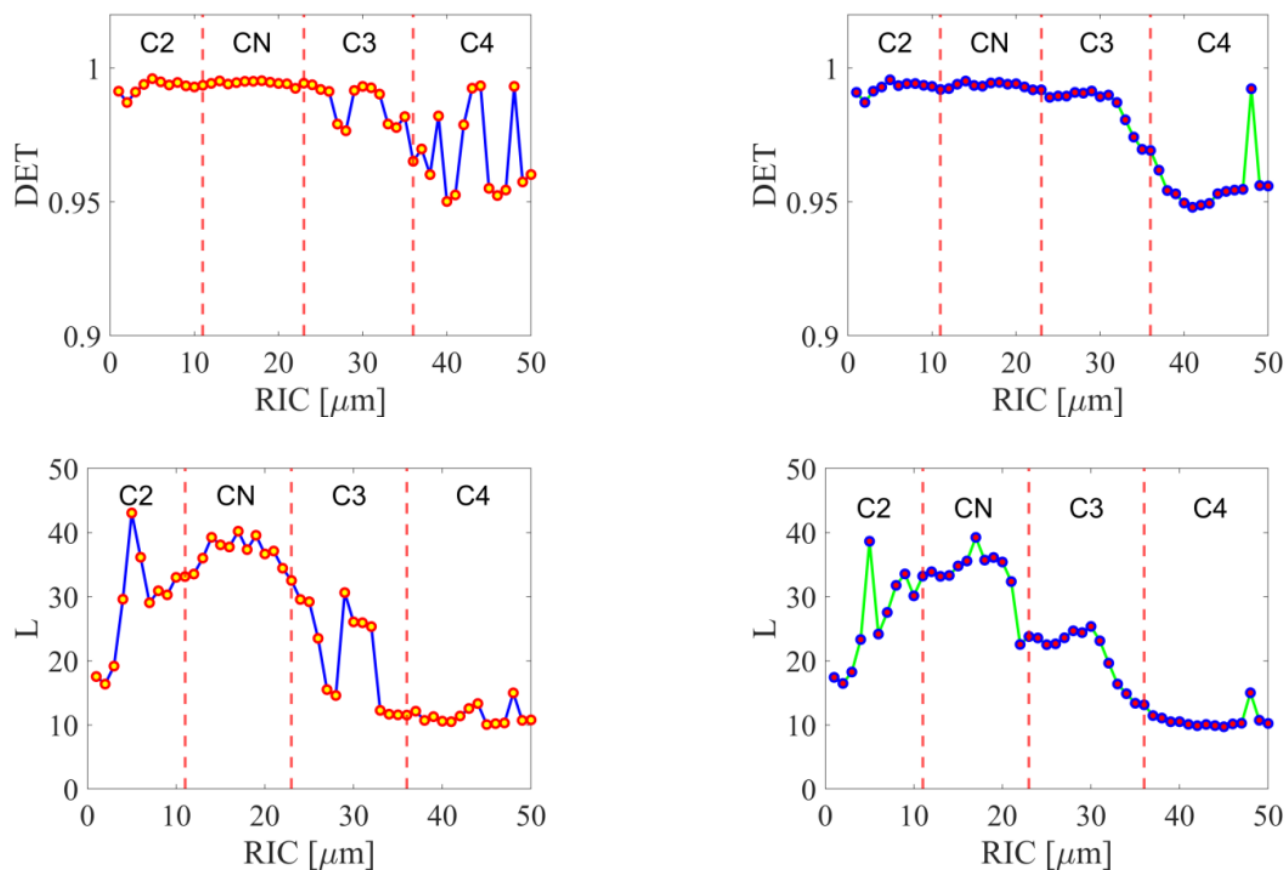

Figure 5: Results of recurrence quantificators based on diagonal lines, i.e. DET - Determinism, $L-$ Averaged diagonal length, with constant damping coefficient (left panel) and variable damping coefficient (right panel).

- Recurrence quantificators based on the vertical lines:

Laminarity denotes the state when the system is trapped in a specific state for a while and changing between two of them. Both for constant and modified damping coefficient, an explicit decrease of laminarity is observed for normal clearance, next the "switch" is observed for clearance bigger than normal. Additionally, the bigger damping factor causes the shift of switching clearance exactly on the border between $\mathrm{CN}$ and $\mathrm{C} 3$ clearance and smooths the decreasing trend for the bigger value of clearance. Similar behaviour is observed in the case of trapping time $T T$ and length of the longest vertical line $V_{\max }$ stabilizing on a specific level for each clearance class, the characteristic switch between clearance classes is observed for $R I C=22 \mu \mathrm{m}$ as well. The difference between the level of vertical-based quantificators can be reflected in the influence of nonlinearity for bigger values of radial clearance. 

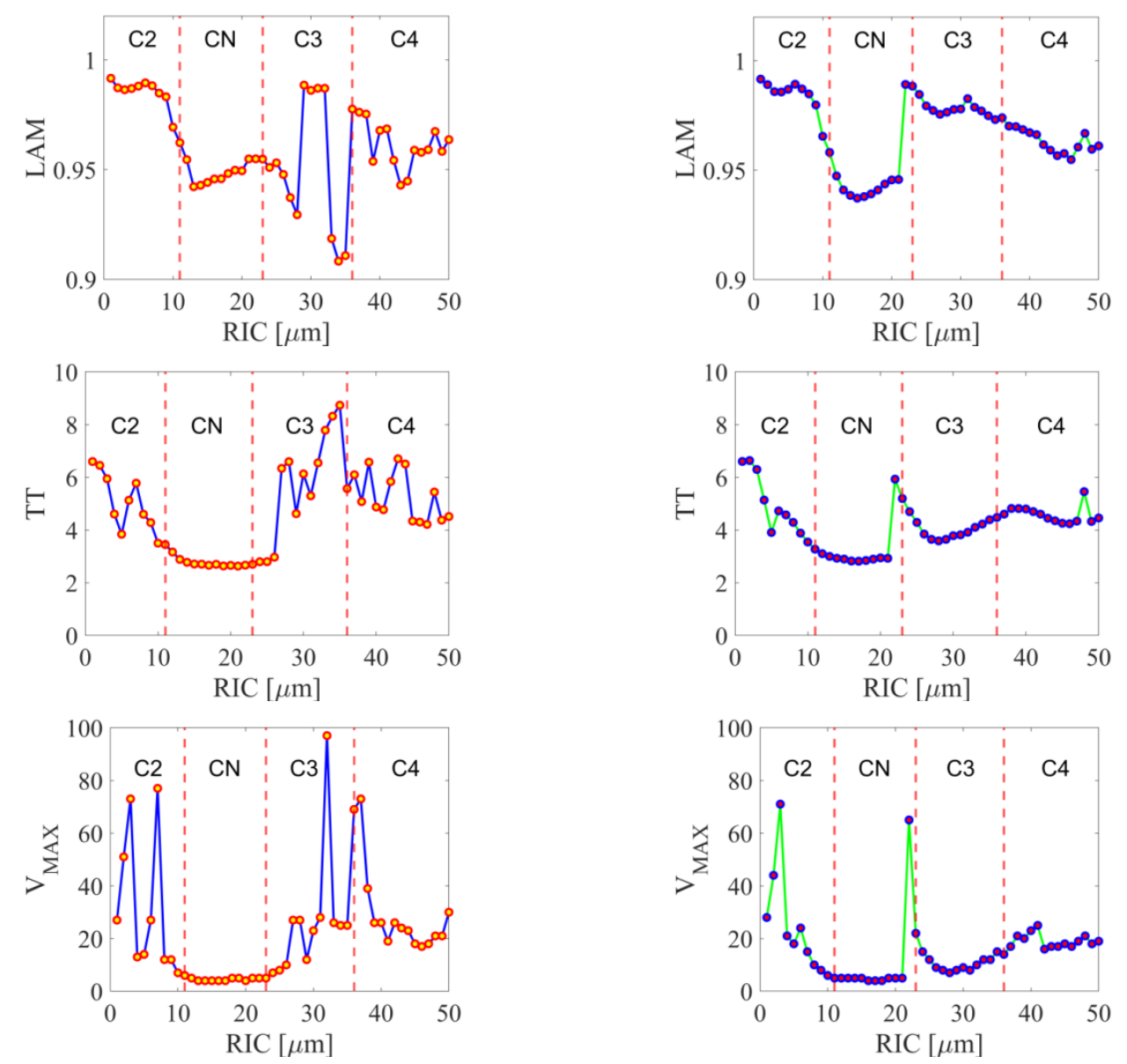

Figure 6: Results of recurrence quantificators based on vertical lines, i.e. LAM - Laminarity, TT Trapping Time, $V_{M A X}$ - Length of the Longest Vertical Line, with constant damping coefficient (left panel) and variable damping coefficient (right panel).

- Recurrence quantificator based on the Recurrence Time:

Only the recurrence time of the second type $T^{(2)}$ (Fig. 7) based on the vertical line structures shows the difference between clearance classes. Mentioned quantificator refers to the detection of transient states and should be applied to the analysis of experimental data, but even based on deterministic data it defines ranges of clearance classes. The recurrence time for small clearances is fluctuating, as the influence of frictional forces on the system's dynamics has a significant impact. For normal clearance $\mathrm{CN}$, it stabilizes on the constant level and for two other clearance classes, it starts to increase again because of more freedom between rolling surfaces. Again as in the case of the previous quantificators, the application of variable damping coefficient helps to avoid unordered fluctuations of the response by a bigger value of clearance.
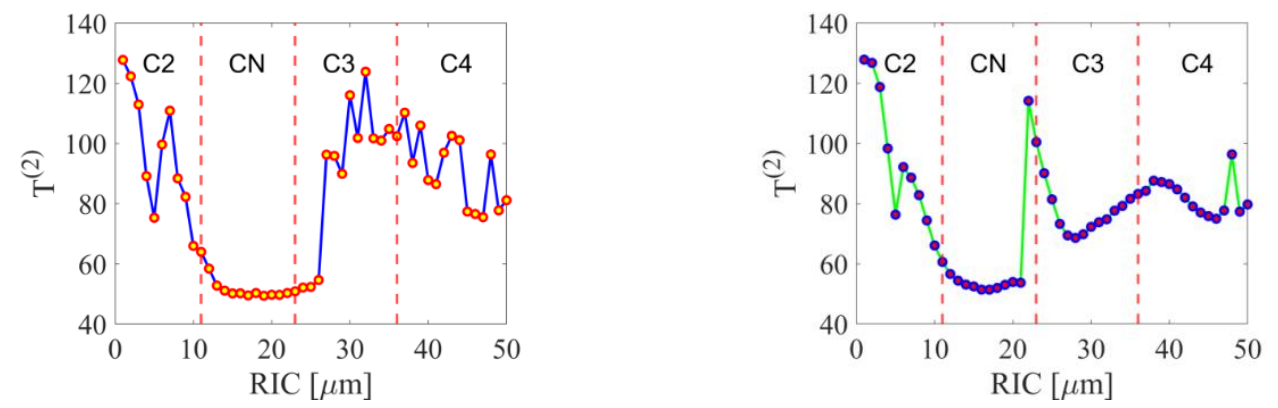

Figure 7: Results of recurrence quantificator based on recurrence time, i.e. $T^{2}$ - recurrence time of the $2^{\text {nd }}$ type, with constant damping coefficient (left panel) and variable damping coefficient (right panel). 
- Recurrence quantificators based on the Probability:

The last group of quantificators is based on the probability (Fig. 8), recurrence period density entropy $T_{r e c}$, clustering $C$, and transitivity TRANS. Regarding the first quantificator, it refers to the uncertainty of the signal similarly as in the case of Shannon entropy. The increased level of $T_{r e c}$ for $\mathrm{C} 2$ and $\mathrm{C} 4$ refers to the influence of friction and the higher amplitude of the vibration of the bearing. The course of clustering and transitivity is inversed, but with both quantificators it is possible to distinguish different clearance classes.
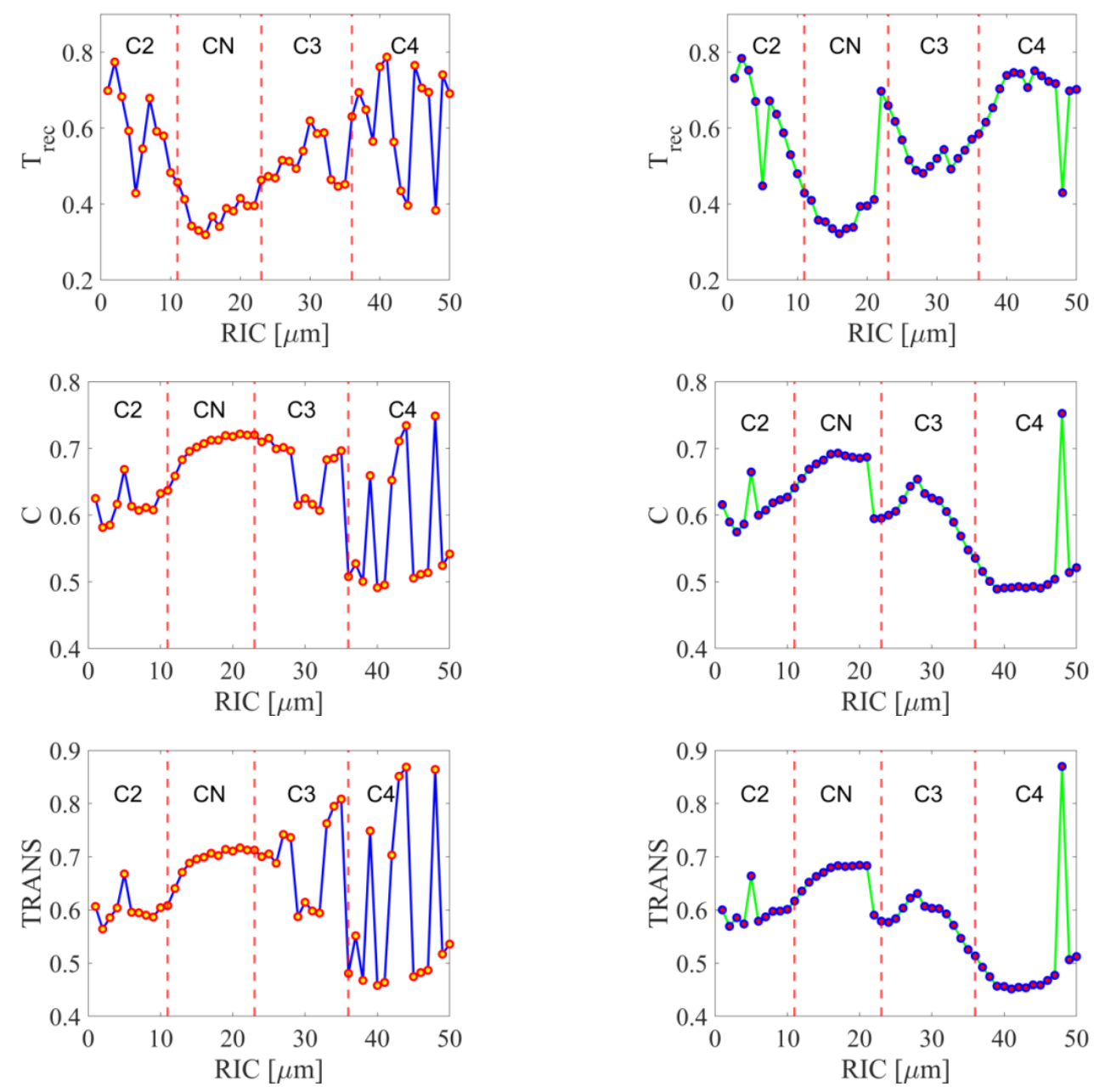

Figure 8: Results of recurrence quantificators based on probability, i.e. $T_{r e c}-$ Recurrence Period Density Entropy, $C$ - Clustering, TRANS - Transitivity, with constant damping coefficient (left panel) and variable damping coefficient (right panel).

Comparing the results of quantificators presented in Figs. 5 to 8 are reflecting the dynamical response of ball bearings with variable radial clearance. Additionally, the application of the variable damping coefficient improved the determination of each quantificators on a specific level simultaneously removing unordered and unknown origin fluctuations. The results obtained are promising and found quantificators can be classified for analysis of experimental data of ball bearing's acceleration response.

\section{CONCLUSIONS}

Over the years, the diagnostics of rolling-element bearings have become an area of interest and more and more refined methods are used for studying the identification of its dynamical response. The basic and the most practical methods in diagnostics of rotational elements are 
based on the frequency domain, which can be referred to as the design and operating conditions of the system identifying the characteristic frequencies. Unfortunately, identification of special behaviour of ball bearings caused by radial clearance, subjected load, or contamination is hardly visible in the frequency domain and there is a demand for the application of more sublime timedomain methods.

It is proposed in this paper to apply the recurrence-based methods for studying the radial clearance effect on the dynamical response of ball bearings and look for its recurrence properties. So far, the characteristic frequency in the spectral domain cannot be indisputably assigned to the specific value of radial clearance and therefore the motivation is to use the timedomain as the source of information on the clearance impact. The complex approach simplifies the analysis of the signal information content by showing specific patterns in form of recurrence plots changing with the variable clearance and providing the quantitative information with recurrence quantificators.

Referring to obtained recurrence plots, the calculation of recurrence quantificators allows finding specific ranges corresponding to the real clearance classes. Then, the dynamical response of a ball bearing stabilizes on the specific level or shows the specific decreasing or increasing trend caused by the influence of frictional force or impacts due to the freedom of balls. Interestingly, following the approach with the variable damping function, the response of quantificators has been smoothed especially at the $\mathrm{C} 4$ clearance class vanishing the unknown fluctuations.

To sum everything up, the recurrence-based methods seem to be useful in the analysis of variable dynamical response in rolling-element bearings caused by the radial clearance. Particularly important was the application of a function with variable damping, which refers to the experimental verification. The next step in the research will be the model development and combining it with the experimental verification implementing the variable clearance and operating velocity.

\section{ACKNOWLEDGEMENT}

The research was financed in the framework of the project Lublin University of Technology - Regional Excellence Initiative, funded by the Ministry of Science and Higher Education (contract no. 030/RID/2018/19).

\section{REFERENCES}

[1] Nikravesh, M.; Naderi, M.; Akbari, G. H.; Bleck, W. (2015). Phase transformations in a simulated hot stamping process of the boron bearing steel, Materials \& Design, Vol. 84, 18-24, doi:10.1016/j.matdes.2015.06.108

[2] Anusha, E.; Kumar, A.; Shariff, S. M. (2020). A novel method of laser surface hardening treatment inducing different thermal processing condition for thin-sectioned 100Cr6 steel, Optics \& Laser Technology, Vol. 125, Paper 106061, 13 pages, doi:10.1016/j.optlastec.2020.106061

[3] Alok, A.; Das, M. (2019). Multi-objective optimization of cutting parameters during sustainable dry hard turning of AISI 52100 steel with newly develop $\mathrm{HSN}^{2}$-coated carbide insert, Measurement, Vol. 133, 288-302, doi:10.1016/j.measurement.2018.10.009

[4] De Moraes, L. D.; Garcia, M. V.; Lopes, J. C.; Fonteque Ribeiro, F. S.; Sanchez, L. E. A.; Foschini, C. R.; de Mello, H. J.; Aguiar, P. R.; Bianchi, E. C. (2019). Performance of SAE 52100 steel grinding using MQL technique with pure and diluted oil, The International Journal of Advanced Manufacturing Technology, Vol. 105, No. 10, 4211-4223, doi:10.1007/s00170-019-04582-5

[5] Kumar, S.; Kumar, P.; Kumar, G. (2021). Degradation assessment of bearing based on machine learning classification matrix, Eksploatacja i Niezawodnosc - Maintenance and Reliability, Vol. 23, No. 2, 395-404, doi:10.17531/ein.2021.2.20 
[6] Cerrada, M.; Sanchez, R.-V.; Li, C.; Pacheco, F.; Cabrera, D.; de Oliveira, J. V.; Vasquez, R. E. (2018). A review on data-driven fault severity assessment in rolling bearings, Mechanical Systems and Signal Processing, Vol. 99, 169-196, doi:10.1016/j.ymssp.2017.06.012

[7] Jasiulewicz-Kaczmarek, M.; Gola, A. (2019). Maintenance 4.0 technologies for sustainable manufacturing - an overview, IFAC-PapersOnLine, Vol. 52, No. 10, 91-96, doi:10.1016/ j.ifacol.2019.10.005

[8] Gola, A. (2019). Reliability analysis of reconfigurable manufacturing system structures using computer simulation methods, Eksploatacja i Niezawodnosc - Maintenance and Reliability, Vol. 21, No. 1, 90-102, doi:10.17531/ein.2019.1.11

[9] Wang, D.; Tsui, K.-L.; Miao, Q. (2017). Prognostics and health management: a review of vibration based bearing and gear health indicators, IEEE Access, Vol. 6, 665-676, doi:10.1109/ ACCESS.2017.2774261

[10] Mishra, C.; Samantaray, A. K.; Chakraborty, G. (2017). Ball bearing defect models: a study of simulated and experimental fault signatures, Journal of Sound and Vibration, Vol. 400, 86-112, doi:10.1016/j.jsv.2017.04.010

[11] Patil, M. S.; Mathew, J.; Rajendrakumar, P. K.; Desai, S. (2010). A theoretical model to predict the effect of localized defect on vibrations associated with ball bearing, International Journal of Mechanical Sciences, Vol. 52, No. 9, 1193-1201, doi:10.1016/j.ijmecsci.2010.05.005

[12] Adamczak, S.; Zmarzły, P. (2019). Research of the influence of the 2D and 3D surface roughness parameters of bearing raceways on the vibration level, Journal of Physics: Conference Series, Vol. 1183, Paper 012001, 10 pages, doi:10.1088/1742-6596/1183/1/012001

[13] Tiwari, M.; Gupta, K.; Prakash, O. (2000). Effect of radial clearance of a ball bearing on the dynamics of a balanced horizontal rotor, Journal of Sound and Vibration, Vol. 238, No. 5, 723756, doi:10.1006/jsvi.1999.3109

[14] Changqing, B.; Qingyu, X. (2006). Dynamic model of ball bearings with internal clearance and waviness, Journal of Sound and Vibration, Vol. 294, No. 1-2, 23-48, doi:10.1016/j.jsv.2005.10.005

[15] Mišković, Ž. Z.; Mitrović, R. M.; Stamenić, Z. V. (2016). Analysis of grease contamination influence on the internal radial clearance of ball bearings by thermographic inspection, Thermal Science, Vol. 20, No. 1, 255-265, doi:10.2298/TSCI150319083M

[16] Miler, D.; Škec, S.; Katana, B.; Žeželj, D. (2019). An experimental study of composite plain bearings: the influence of clearance on friction coefficient and temperature, Strojniski vestnikJournal of Mechanical Engineering, Vol. 65, No. 10, 547-556, doi:10.5545/sv-jme.2019.6108

[17] Xu, M.; Feng, G.; He, Q.; Gu, F.; Ball, A. (2020). Vibration characteristics of rolling element bearings with different radial clearances for condition monitoring of wind turbine, Applied Sciences, Vol. 10, No. 14, Paper 4731, 19 pages, doi:10.3390/app10144731

[18] Meier, N.; Biyani, Y.; Georgiadis, A. (2018). Determination of bearing clearance by the application of neural networks, Proceedings of 2018 IEEE Sensors, 4 pages, doi:10.1109/ ICSENS.2018.8589587

[19] Knežević, I.; Živković, A.; Rackov, M.; Kanović, Ž.; Buljević, A.; Bojanić Šejat, M.; Navalušić, S. (2021). Prediction of radial clearance based on bearing vibration using artificial neural network, IOP Conference Series: Material Science and Engineering, Vol. 1009, Paper 012028, 5 pages, doi:10.1088/1757-899X/1009/1/012028

[20] Yakout, M.; Nassef, M. G. A.; Backer, S. (2019). Effect of clearances in rolling element bearings on their dynamic performance, quality and operating life, Journal of Mechanical Science and Technology, Vol. 33, No. 5, 2037-2042, doi:10.1007/s12206-019-0406-y

[21] Leturiondo, U.; Salgado, O.; Galar, D. (2016). Multi-body modelling of rolling element bearings and performance evaluation with localised damage, Eksploatacja i Niezawodnosc - Maintenance and Reliability, Vol. 18, No. 4, 638-648, doi:10.17531/ein.2016.4.20

[22] Zeillinger, R.; Kottritsch, H. (1996). Damping in a rolling bearing arrangement, Evolution: Technology Magazine from SKF, from https://evolution.skf.com/damping-in-a-rolling-bearingarrangement/, accessed on 17-04-2021

[23] Bizarre, L.; Nonato, F.; Cavalca, K. L. (2018). Formulation of five degrees of freedom ball bearing model accounting for the nonlinear stiffness and damping of elastohydrodynamic point contacts, Mechanism and Machine Theory, Vol. 124, 179-196, doi:10.1016/j.mechmachtheory.2018.03.001 
[24] Syta, A.; Jonak, J.; Jedliński, Ł.; Litak, G. (2012). Failure diagnosis of a gear box by recurrences, Journal of Vibration and Acoustics, Vol. 134, No. 4, Paper 041006, 8 pages, doi:10.1115/ 1.4005846

[25] Xiao, D.; Huang, Y.; Qin, C.; Shi, H.; Li, Y. (2019). Fault diagnosis of induction motors using recurrence quantification analysis and LSTM with weighted BN, Shock and Vibration, Vol. 2019, Paper 8325218, 14 pages, doi: $10.1155 / 2019 / 8325218$

[26] Syta, A.; Czarnigowski, J.; Jakliński, P. (2021). Detection of cylinder misfire in an aircraft engine using linear and non-linear signal analysis, Measurement, Vol. 174, Paper 108982, 10 pages, doi:10.1016/j.measurement.2021.108982

[27] Wang, Y.; Yang, H. Y.; Chen, G.; Jia, Y. J. (2021). Influence of fit clearance on the stability of "three oil film-rotor" structure, International Journal of Simulation Modelling, Vol. 20, No. 1, 170180, doi:10.2507/IJSIMM20-1-CO2

[28] Pabiszczak, S.; Staniek, R. (2020). Investigation of contact stresses in the eccentric rolling transmission, International Journal of Simulation Modelling, Vol. 19, No. 1, 41-52, doi:10.2507/IJSIMM19-1-500

[29] Cheng, L. Z.; Liu, D. K.; Wang, Y.; Chen, A. Q. (2019). Load distribution and contact of axle box bearings in electric multiple units, International Journal of Simulation Modelling, Vol. 18, No. 2, 290-301, doi:10.2507/IJSIMM18(2)475

[30] Yang, X.; Li, Y.; Liu, G.; Wang, J. (2019). Effect of surface roughness on elastohydrodynamic lubrication performance of cylindrical roller bearing, Technical Gazette, Vol. 26, No. 3, 710-721, doi:10.17559/TV-20190104091451

[31] Ambrożkiewicz, B.; Litak, G.; Georgiadis, A.; Meier, N.; Gassner, A. (2021). Analysis of dynamic response of a two degrees of freedom (2-DOF) ball bearing nonlinear model, Applied Sciences, Vol. 11, No. 2, Paper 787, 23 pages, doi:10.3390/app11020787

[32] Marwan, N.; Carmen Romano, M.; Thiel, M.; Kurths, J. (2007). Recurrence plots for the analysis of complex systems, Physics Reports, Vol. 438, No. 5-6, 237-329, doi:10.1016/ j.physrep.2006.11.001

[33] Eckmann, J.-P.; Olifsson Kamphorst, S.; Ruelle, D. (1987). Recurrence plots of dynamical systems, Europhysics Letters, Vol. 4, No. 9, 973-977, doi:10.1209/0295-5075/4/9/004

[34] Trulla, L. L.; Giuliani, A.; Zbilut, J. P.; Webber, C. L. (1996). Recurrence quantification analysis of the logistic equation with transients, Physics Letters A, Vol. 223, No. 4, 255-260, doi:10.1016/S0375-9601(96)00741-4

[35] Potsdam Institute for Climate Impact Research - Cross Recurrence Plot Toolbox 5.22, from https://tocsy.pik-potsdam.de/CRPtoolbox/, accessed on 30-04-2021 